Article

\title{
Methods for Determination of the Degree of Iron Oxidation in $\mathrm{LiFePO}_{4}$
}

\author{
Fyodor Malchik ${ }^{1, *}$, Andrey Kurbatov ${ }^{1}$ (D), Alina Galeyeva ${ }^{1}$, Duysek Kamysbaev ${ }^{1}$ \\ and Alexandru-Horatiu Marincas ${ }^{2}$ \\ 1 Center of Physical and Chemical Methods of Research and Analysis, al-Farabi Kazakh National University, \\ 71 al-Farabi Ave., Almaty 050040, Kazakhstan; kurbatovap@gmail.com (K.A.); alinex@bk.ru (G.A.); \\ kamysbayev@mail.ru (K.D.) \\ 2 Faculty of Chemistry and Chemical Engineering, Babes Bolyai University, 11 Arany Janos Street, \\ 400028 Cluj-Napoca, Romania; horatiu.marincas@yahoo.com \\ * Correspondence: Frodo-007@mail.ru; Tel.: +7-771-457-6720
}

Received: 23 August 2017; Accepted: 20 September 2017; Published: 24 September 2017

\begin{abstract}
The disposal of $\mathrm{LiFePO}_{4}$ (LFP) cathode material through oxidation in an air atmosphere is explained by its high chemical activity and high surface area (especially for nanoparticles). In this article, new methods for the determination of the degree of iron oxidation in LFP (oxidation degree) are taken into consideration, specifically those which do not require complicated hardware support. The proposed methods are based on electrochemical oxidation (coulometric method) and chemical oxidation (chemical oxidation in alkaline and acidic solutions). As an arbitration method for analyzing the iron state, the method of Mössbauer spectroscopy (being the most proven and reliable method) was chosen. With respect to the proposed methods for determination of the oxidation degree, the most reliable and quick approach is the titrimetric method (oxidation in an acidic medium), which is in good correlation with Mossbauer spectroscopy. The coulometric method is also able to determine the material oxidation degree (with some approximation), but it requires a number of conditions in order to eliminate errors.
\end{abstract}

Keywords: $\mathrm{LiFePO}_{4}$ cathode material; lithium ion battery; oxidation degree; chemical oxidation

\section{Introduction}

Lithium ion batteries are suitable power sources for newly developed mobile devices (cellphones, laptops, cameras, etc.) because of their superior electrochemical characteristics in comparison with classical batteries (Ni-Cd, Ni-MH). Lithium ion batteries possess high energy density, improved life cycling performance, and higher working potential.

Cathode materials are one of the key components of Li-ion batteries, and can determine capacity and power performance. Olivine-type lithium iron phosphate material is a very promising cathode material for lithium-ion batteries due to its high theoretical capacity $(170 \mathrm{mAh} / \mathrm{g})$ and it has an average charge/discharge voltage of $3.4 \mathrm{~V}$ [1]. In addition, the material is quite cheap and it is environmentally friendly, with good thermal and cycling stability. The main disadvantages are low electronic and ionic conductivity because of the slow rate of lithium ion diffusion through the material's solid structure [2].

In general, the following reaction (1) describes the $\mathrm{LiFePO}_{4}$ cathode material's behavior in a lithium-ion battery:

$$
\mathrm{LiFePO}_{4}-x e^{-} \rightleftarrows(1-x) \mathrm{LiFePO}_{4}+x \mathrm{FePO}_{4}+x \mathrm{Li}^{+}
$$

This process in the forward direction can be carried out chemically in solution, using the Ox-Red reaction. In this case, the chemical reaction of $\mathrm{LiFePO}_{4}$ oxidation can proceed either through a 
solid-phase mechanism (1) or with the dissolution of $\mathrm{LiFePO}_{4}$ crystals. Dissolution occurs in acidic aqueous solutions $(\mathrm{pH}<4)$, presumably due to the replacement of lithium ions in $\mathrm{LiFePO}_{4}$ with hydrogen ions to form a soluble hydrogen phosphate. In particular, the ability of $\mathrm{LiFePO}_{4}$ dissolution in acidic media helps to determine the mass fraction of carbon [3]. Usually, for the dissolution of lithium iron phosphate, a mixture of sulfuric $(50 \%)$ and hydrochloric $(50 \%)$ acids (1:1) is used while heating and stirring the solution. Under these conditions, insoluble carbon remains as a precipitate which can be filtered out, dried, and gravimetrically determined.

The dissolution of $\mathrm{LiFePO}_{4}$ in an acidic medium can be used to create an easy and fast method for determining the degree of oxidation of this material $\left(w\left(\mathrm{Fe}^{3+}\right)=\frac{m\left(\mathrm{Fe}^{3+}\right)}{m\left(\mathrm{Fe}^{2+}\right)}\right)$. Determination of the degree of oxidation of $\mathrm{LiFePO}_{4}$ cathode material is an urgent task, because this material is fairly active and can be easily oxidized from the surface during storage in an oxygen atmosphere. In addition, there are a number of synthesis methods where trivalent iron compounds are used as precursors $[4,5]$, whereas in certain synthesis conditions, the presence of $\mathrm{Li}^{+}$and $\mathrm{PO}_{4}{ }^{3-}$ ions should lead to $\mathrm{LiFePO}_{4}$ formation. Controlling the iron oxidation state during synthesis is very important, because if $\mathrm{Fe}^{3+}$ ions remain into the compound, they will decrease the mass of the active material $\left(\mathrm{LiFePO}_{4}\right)$ and will prevent reversible interaction/deintercalation of lithium ions during battery cycling. For example, even in the hydrothermal synthesis method [6] where the divalent iron precursor $\left(\mathrm{FeSO}_{4}\right)$ is used, in the absence of a reducing agent (ascorbic acid), $\mathrm{LiFePO}_{4}$ with a $\mathrm{Fe}^{3+}$ impurity is obtained. The obtained $\mathrm{LiFePO}_{4}$ is significantly lower in electrochemical characteristics with respect to $\mathrm{LiFePO}_{4}$ obtained by the same method in the presence of an inert atmosphere or reducing agent.

In a neutral or alkaline medium, this material is insoluble. Using the chemical reaction of oxidation in a non-acidic medium, it is possible to determine the kinetic parameters of reaction (1), such as activation energy and diffusion coefficient [7]. Moreover, the obtained transport parameters will characterize the cathode material itself directly, and not the total characteristics of the composite electrode (binder, electroconductive additive, active material). Such transport parameters (summary) are obtained through different electrochemical methods (GITT, PITT, EIS) [8,9]. Any suitable oxidizing agents in various media can carry out oxidative delithiation of $\mathrm{LiFePO}_{4}$. For example, the chemical oxidation of $\mathrm{LiFePO}_{4}$ in organic media was investigated using oxidants such as 10-methylphenothiazine (MPT) [10] or nitronium tetrafluoroborate $\left(\mathrm{NO}_{2} \mathrm{BF}_{4}\right)$ in acetonitrile [11] The use of organic solvents most often requires the use of an inert atmosphere and a complete lack of water, as seen in the previously mentioned works $[10,11]$. In organic media, the diffusion restrictions in solution are more substantial due to their increased viscosity. Since $\mathrm{LiFePO}_{4}$ is stable in aqueous media, chemical delithiation is most convenient in them. In [12] chemical delithiation was realized using hydrogen peroxide as an oxidizer in a weak acidic medium, thus permitting the determination of the kinetic parameters of the delithiation process.

In this article, the oxidation degree of the lithium iron phosphate was determined using chemical oxidation in aqueous solutions with $\mathrm{pH}<4$ and $\mathrm{pH}>4$, respectively, (Figure 1). 


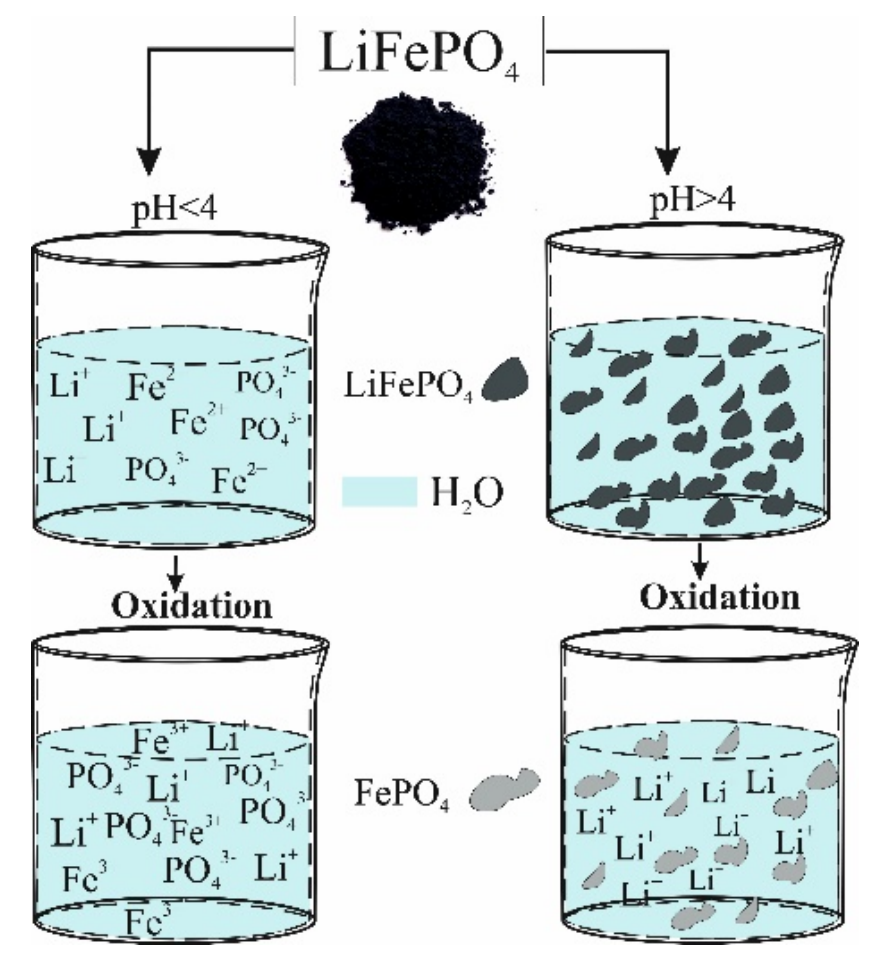

Figure 1. Scheme of $\mathrm{LiFePO}_{4}$ oxidation in an aqueous medium at different $\mathrm{pH}$.

\section{Materials and Methods}

Firstly, $\mathrm{FePO}_{4} \cdot 2 \mathrm{H}_{2} \mathrm{O}$, as the main precursor for $\mathrm{LiFePO}_{4}$ synthesis, was prepared. $\mathrm{FeCl}_{3} \cdot 6 \mathrm{H}_{2} \mathrm{O}$ (Sigma Aldrich 98\% Laborpharma LTD Almaty, Kazakhstan), $\left(\mathrm{NH}_{4}\right)_{2} \mathrm{HPO}_{4} \cdot 12 \mathrm{H}_{2} \mathrm{O}$ (Sigma Aldrich $\geq 99.0 \%$ ) and $\mathrm{CH}_{3} \mathrm{COONa} \cdot 3 \mathrm{H}_{2} \mathrm{O}(\geq 99.0 \%)$ solutions in a stoichiometric ratio were mixed together slowly dropwise and then stirred for several hours. Then, the sample was collected by filtration, washed several times with deionized water, and dried at $100{ }^{\circ} \mathrm{C}$ in air atmosphere for $12 \mathrm{~h}$.

$\mathrm{LiFePO}_{4} / \mathrm{C}$ was synthesized by the carbothermal reduction method from the following agents: $\mathrm{LiAc} \cdot 2 \mathrm{H}_{2} \mathrm{O}$ (Sigma Aldrich $\geq 99.0 \%$ ), and as-synthesized $\mathrm{FePO}_{4} \cdot 2 \mathrm{H}_{2} \mathrm{O}$ and stearic acid (Sigma Aldrich $98 \%$ ) as the reducing agent and carbon source, respectively [5]. Stearic acid (15\% by weight of $\mathrm{FePO}_{4} \cdot 2 \mathrm{H}_{2} \mathrm{O}$ ) was dissolved through stirring in $100 \mathrm{~mL}$ of ethanol at $60{ }^{\circ} \mathrm{C}$. After complete dissolution, $\mathrm{LiAc} \cdot 2 \mathrm{H}_{2} \mathrm{O}$ and $\mathrm{FePO}_{4} \cdot 2 \mathrm{H}_{2} \mathrm{O}(1: 1$ molar ratio) were added. The resulting mixture was heated at $90{ }^{\circ} \mathrm{C}$ to evaporate the solvent until a slurry was formed, which was dried in an oven at $100{ }^{\circ} \mathrm{C}$ in an air atmosphere for $12 \mathrm{~h}$. The resulting mixture (powder) was calcined at $600{ }^{\circ} \mathrm{C}$ for $6 \mathrm{~h}$ in an argon atmosphere.

X-ray diffraction (XRD) analysis of the synthesized sample was carried out on a DRON-3M diffractometer. Sampling modes were as follows: the voltage on the $\mathrm{X}$-ray tube was $30 \mathrm{kV}$, the tube current was $30 \mathrm{~mA}$, the pitch of the goniometer was $0.05^{\circ} 2 \theta$, and the time of the intensity measurement at the point was $1.0 \mathrm{~s}$. Figure 2 shows the X-ray powder diffraction spectrum recorded under Bragg-Brentano geometry in diffraction angle ranging from $10^{\circ}$ to $70^{\circ}$ of the synthesized $\mathrm{LiFePO}_{4}$ powder sample. All diffraction peaks are indexed to an orthorhombic crystal structure with the Pnma space group. The estimated lattice parameters are $\mathrm{a}=10.412 \AA, \mathrm{b}=6.011 \AA, \mathrm{c}=4.696 \AA$ and $\mathrm{V}=291.4 \AA^{3}$, which are close to the corresponding constants of JCPDS (PDF No. 83-2092) data (Table 1) $[13,14]$. 


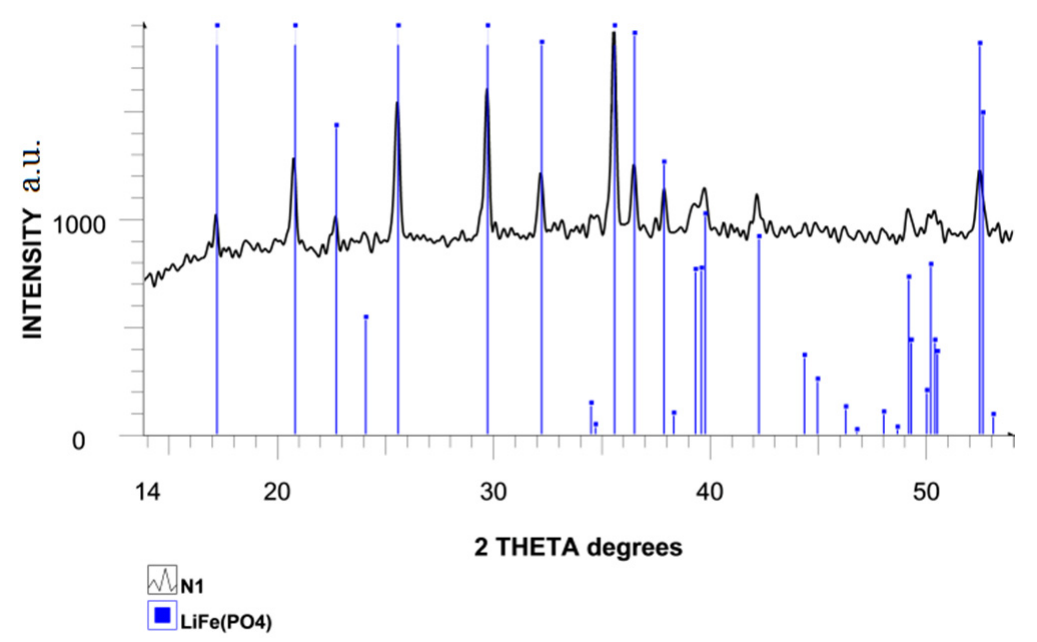

Figure 2. X-ray diffraction (XRD) pattern of synthesized $\mathrm{LiFePO}_{4} / \mathrm{C}$.

Table 1. The lattice parameter values of the $\mathrm{LiFePO}_{4} / \mathrm{C}$ sample and standard data.

\begin{tabular}{ccccc}
\hline \multirow{2}{*}{ Sample } & \multicolumn{4}{c}{ Lattice Parameters } \\
\cline { 2 - 5 } & $\mathbf{a}, \AA$ & $\mathbf{b}, \AA$ & c, $\AA$ & V, $\AA^{\mathbf{3}}$ \\
\hline $\mathrm{LiFePO}_{4}$ & 10.412 & 6.011 & 4.696 & 293.9 \\
\hline No. 83-2092 & 10.33 & 6.01 & 4.69 & 291 \\
\hline
\end{tabular}

The Mössbauer spectrum of the sample was obtained on a MS 1104Em spectrometer. The source was cobalt 57 in the chromium matrix, with an activity of $100 \mathrm{mCi}$ (the temperature of the spectroscopy was $293 \mathrm{~K})$. Mössbauer spectroscopy is very sensitive in terms of characterizing atoms with different valence states, as it provides a direct scrutiny of atomic information. Therefore, Mössbauer spectroscopy measurement was carried out to analyze the existence of $\mathrm{Fe}^{3+}$-containing species. Figure 3 shows the Mössbauer spectroscopy of the as-prepared $\mathrm{LiFePO}_{4} / \mathrm{C}$. One symmetric doublet is dominant, with an isomer shift (IS) of $1.22 \mathrm{~mm} / \mathrm{s}$ and quadrupole splitting (QS) of $2.94 \mathrm{~mm} / \mathrm{s}$, which is typical for octahedral $\mathrm{Fe}^{2+}$ in $\mathrm{LiFePO}_{4}-92 \%$ [15]. Another minor doublet was observed, which can be attributed to $\mathrm{Fe}^{3+}$ with a typical IS value $(0.32 \mathrm{~mm} / \mathrm{s})$ and $\mathrm{QS}$ of $0.86 \mathrm{~mm} / \mathrm{s}-8 \%$.

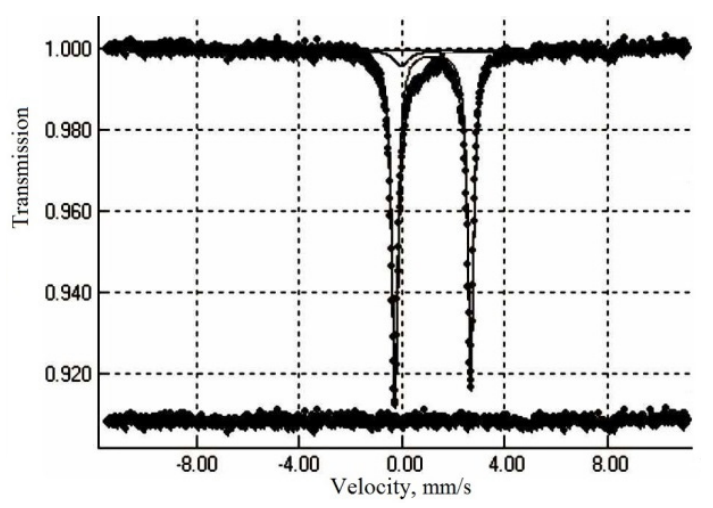

Figure 3. Mössbauer spectrum of the synthesized $\mathrm{LiFePO}_{4} / \mathrm{C}$.

The carbon content of the obtained synthesized $\mathrm{LiFePO}_{4} / \mathrm{C}(\mathrm{LFP} / \mathrm{C})$ was determined using the gravimetric method, by dissolving a known mass of LFP/C in concentrated sulfuric acid, followed by carbon extraction from the sample. The results of the analysis showed the presence of $4 \%$ carbon. 
The fractional composition of synthesized $\mathrm{LiFePO}_{4} / \mathrm{C}$ was determined using a Photocor Compact (Photocor) particle size analyzer. The sample is characterized by a narrow size distribution interval with an average particle diameter of $175 \mathrm{~nm}$ (Figure 4b). Figure 4a shows the High Resolution Scanning Electron Microscopy (HRSEM) image of nano-crystalline $\mathrm{LiFePO}_{4} / \mathrm{C}$ powder. A branch-like morphology with continuous contacts between the particles was observed. The grain sizes vary from $100 \mathrm{~nm}$ to $200 \mathrm{~nm}$ with similar pore size.
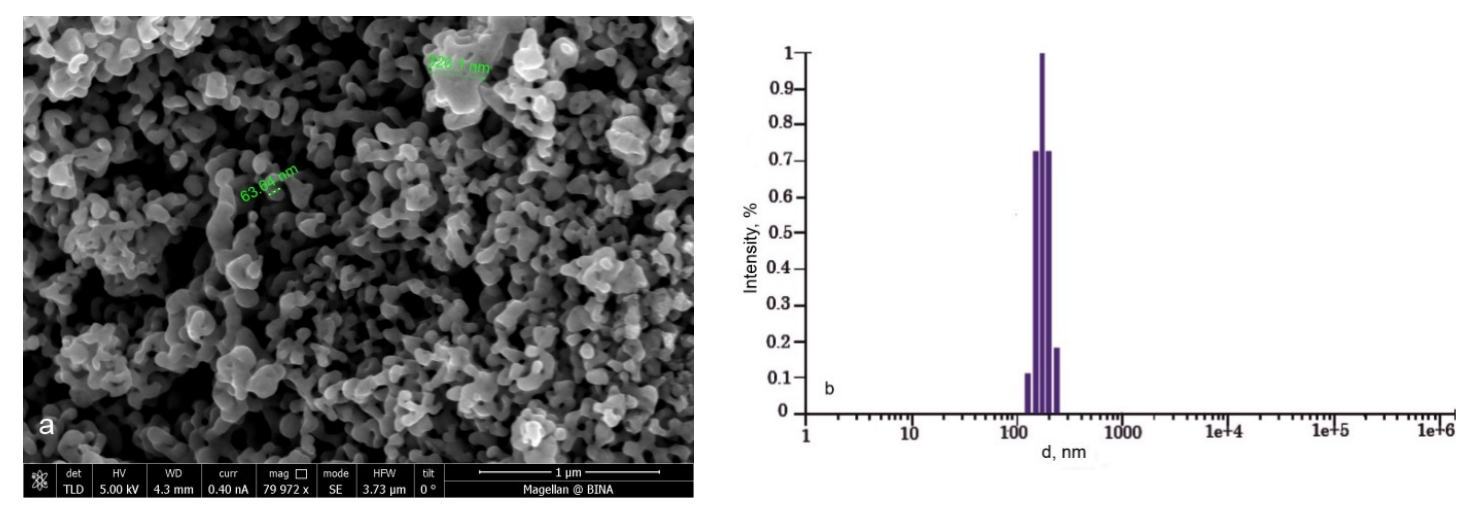

Figure 4. Morphology of synthesized $\mathrm{LiFePO}_{4} / \mathrm{C}$ : (a) High Resolution Scanning Electron Microscopy HRSEM image; (b) particle size distribution.

Electrochemical tests were carried out in 2032 coin-type cell, with a lithium anode, synthesized LFP/C as part of the cathode, and Celgard 2400 as the membrane. The cathode was prepared by mixing $\mathrm{LiFePO}_{4} / \mathrm{C}$ with Super P conductive carbon and polyvinylidene fluoride PVDF in weight ratio of 80:10:10. The cell was assembled in a glove box in argon atmosphere. The electrolyte was a standard solution of $1 \mathrm{M} \mathrm{LiPF}_{6}$ in ethylene carbonate:dimethyl carbonate EC:DMC (1:1). After assembly, the cell was aged for $12 \mathrm{~h}$ to impregnate the membrane material and electrodes with electrolytes.

\section{Results and Discussion}

The instrumental methods used to determine the oxidation degree of the $\mathrm{LiFePO}_{4}$ cathode material, such as Mössbauer spectroscopy and XRD, are reliable methods, but require adequate hardware and skills. In case of lacking the necessary equipment or in case of an express analysis of the oxidation degree of synthesized material, one may try to use a number of non-traditional methods.

\subsection{Coulometric Method}

Theoretically, the oxidation degree can be determined coulometrically using the galvanostatic mode, knowing the exact mass of the active material and the mass of all additives (PVDF, carbon). The oxidation degree in this case will be the ratio between the practically obtained capacity (calculated for the active material) and the theoretical capacity (170 mAh/g), assuming a $100 \%$ yield for material conversion. However, strict intra-diffusion limitations associated with low ionic conductivity of this material make this approach difficult to apply because of low-current necessity and uncertainty associated with an a priori lack of confidence in the $100 \%$ conversion during delithiation/lithiation. In our case, the charge and discharge capacities of the synthesized material reach values of 154.1 and $152.7 \mathrm{mAh} / \mathrm{g}$, respectively, at a current rate of $0.1 \mathrm{C}$ (Figure $5 \mathrm{a}$ ). Using the above-mentioned formula for the degree of oxidation, a conversion percentage of $90.6 \%$ was calculated. This value is close enough to the value determined by Mossbauer spectroscopy (92\%). However, one cannot be sure that there is $100 \%$ yield of active material at such low currents, and the remaining $\approx 10 \%$ of the inactive material should be ferric compound impurities. At higher currents $(>1 \mathrm{C})$, the practical capacity of this material is significantly lower (1 C-145.5; 2 C-132.3; 5 C-113.1; 10 C-91.2; 20 C-65.0) (Figure 5b). 
This is connected with the aforementioned diffusion limitations. Therefore, the coulometric method for determination of the degree of oxidation of the material can be applied only at low current densities.

Synthesized $\mathrm{LiFePO}_{4} / \mathrm{C}$ is a good cathode material capable of operating even at high currents. The material was cycled for 20 times at $20 \mathrm{C}$ without severe degradation and an average charge/discharge capacity of $65.0 \mathrm{mAh} / \mathrm{g}$ was measured (Figure $5 \mathrm{~b}$ ). This material's performance is strictly related to its branched structure and low particle size (Figure 4a,b). It is well-known that the uniform particle size distribution leads to the uniform depth of charge/discharge of each particle, which increase the material's cycling life and enhance the global battery performance.
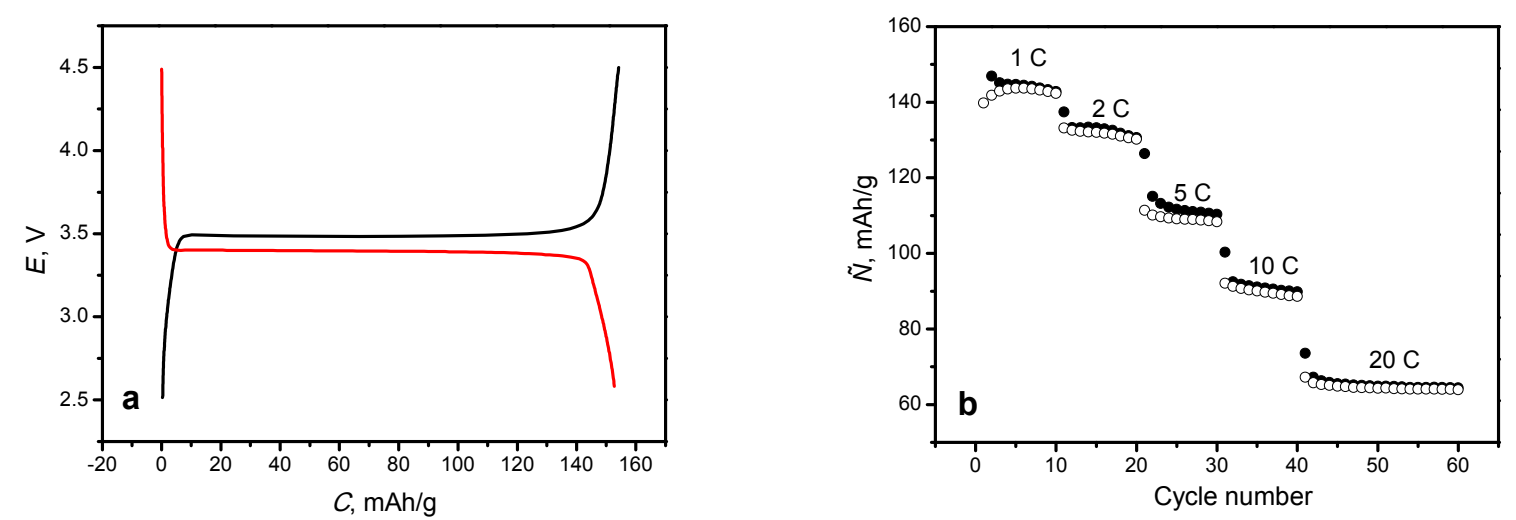

Figure 5. Electrochemical characteristics of synthesized material: (a) the second charge/discharge curve at $0.1 \mathrm{C} ;(\mathbf{b})$ cycling at different $\mathrm{C}$ rate.

\subsection{Chemical Oxidation in Alkaline Solution}

By using the chemical delithiation reaction in an alkaline aqueous medium, it is also possible to determine the oxidation degree of the material by establishing the consumed amount of oxidant or obtained oxidation product (lithium cation). Hydrogen peroxide was chosen as the oxidizing agent, because it does not form insoluble compounds during its reduction and is stable in alkaline medium over time.

The reaction of complete oxidation (chemical delithiation) without the material dissolution can be expressed by the following Equation (2):

$$
2 \mathrm{LiFePO}_{4}+\mathrm{H}_{2} \mathrm{O}_{2} \rightarrow 2 \mathrm{FePO}_{4}+2 \mathrm{Li}^{+}+2 \mathrm{OH}^{-}
$$

By determining the precise amount of extracted (deintercalated) lithium in the liquid phase upon the complete oxidation process, the oxidation degree can be assessed by $\left(w(\mathrm{Ox})=\frac{m\left(\mathrm{Li}_{\mathrm{aq}}^{+}\right)}{m\left(\mathrm{Li}_{\mathrm{LiFPO}}^{+}\right)}\right)$.

To carry out the chemical oxidation of $\mathrm{LiFePO}_{4}$, a covered glass cell was used. A platinum and a $\mathrm{pH}$ glass electrode (relative to the silver-chloride reference electrode) were installed to measure the Ox-Red potential and the $\mathrm{pH}$ of the solution, respectively. The lithium concentration in the solution was determined using a lithium-selective electrode; the response time was three seconds. All measurements were carried out using a universal ionometer I-160 MI with automatic data recording (Figure 6).

$\mathrm{LiFePO}_{4} / \mathrm{C}$ powder of known mass was added to the alkalized solution $(V=100 \mathrm{~mL})$ of hydrogen peroxide. The amount of hydrogen peroxide was 100 times higher relatively to LFP/C. To alkalize the solution to a pH equal to 10 , several drops of concentrated $\mathrm{NH}_{4} \mathrm{OH}$ solution were added. The oxidation process was carried out with constant mixing to distribute the powder evenly throughout the entire solution volume. 


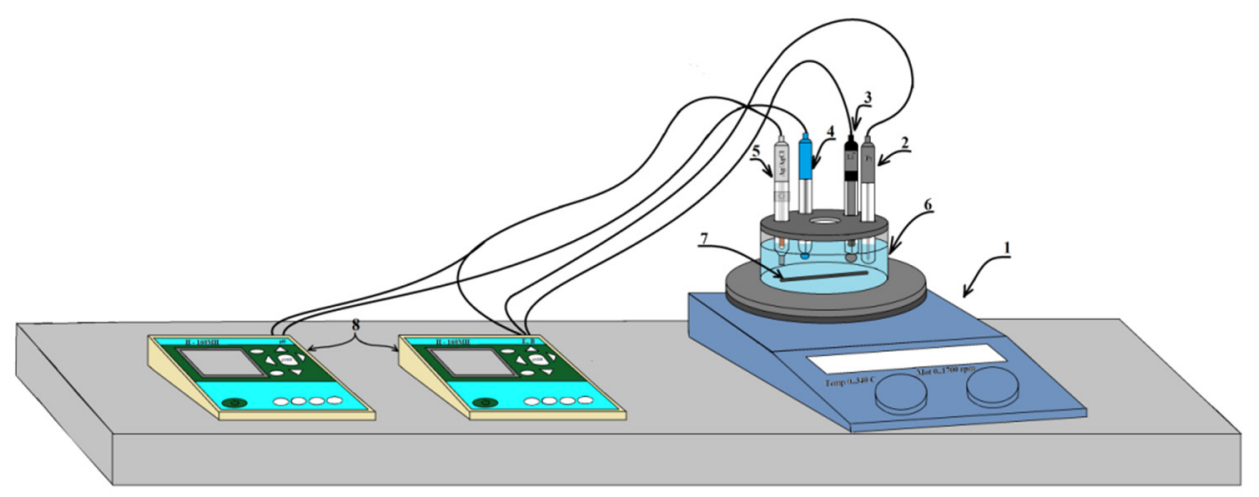

Figure 6. Schematic illustration of the oxidation equipment. 1-magnetic stirrer; 2-platinum electrode; 3-Li selective electrode; 4- $\mathrm{pH}$ glass electrode, 5- $\mathrm{Ag} / \mathrm{AgCl}$ electrode; 6-glass cell; 7-stirrer; 8-ionometer.

Figure 7 shows the degree of delithiation dependence versus time at different temperatures. The chemical oxidation process is fully realized at all temperatures and the delithiation degree is close to $100 \%\left(29^{\circ} \mathrm{C}-2000 \mathrm{~s}, 40{ }^{\circ} \mathrm{C}-1300 \mathrm{~s}, 50{ }^{\circ} \mathrm{C}-800 \mathrm{~s}\right)$. Despite that, in our case, the delithiation degree equals $99.8 \%$, which is much higher than the value determined by Mössbauer spectroscopy. According to the results of Mössbauer spectroscopy, the oxidation percentage of $\mathrm{LiFePO}_{4} / \mathrm{C}$ should not be higher than $92 \%$. However, in this case we measured the total amount of lithium that can be extracted from $92 \% \mathrm{LiFePO}_{4}$ and from $8 \%$ impurities (since the Li:Fe ratio was 1:1 in the synthesis). Unlike the coulometric method, chemical oxidation in alkaline solution provides mistaken results. Probably, the results were influenced by the indirect determination of divalent iron ions, along with the lithium ions from the solution.

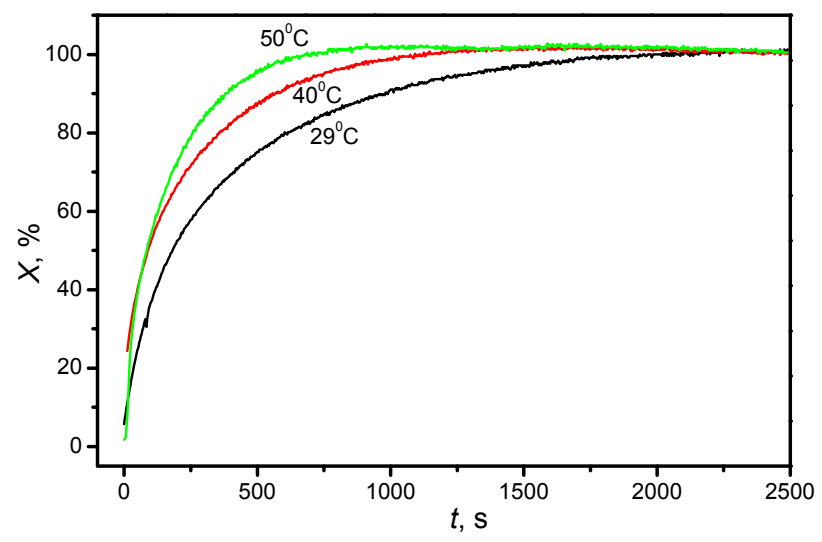

Figure 7. Kinetic curves of $\mathrm{LiFePO}_{4} / \mathrm{C}$ chemical delithiation process at different temperatures.

Chemical oxidation without material dissolution can serve as a method for determining the transport parameters of the chemical delithiation process, such as diffusion coefficient and activation energy [11-13].

\subsection{Chemical Oxidation in Acidic Medium}

Unlike alkaline solutions, $\mathrm{LiFePO}_{4}$ dissolves into $\mathrm{Li}^{+}, \mathrm{Fe}^{2+}$, and $\mathrm{PO}_{4}{ }^{3-}$ ions in strong acidic medium. This is very convenient for determining the degree of oxidation of the material, because chemical oxidation in acidic solution allows a homogenous oxidation reaction of $\mathrm{Fe}^{2+}$ to $\mathrm{Fe}^{3+}$.

In this paper, the oxidation in an acid medium was used to determine the degree of oxidation of the synthesized material. The degree of oxidation of of $\mathrm{LiFePO}_{4}$ was determined by Ox-Red 
titration with potassium dichromate of a dissolved sample in an acidic medium. The known mass of $\mathrm{LiFePO}_{4} / \mathrm{C}$ was added to a $50-\mathrm{mL}$ volume of sulfuric acid solution $(50 \%)$ with stirring, and after complete dissolution, the resulting solution was titrated with $0.05 \mathrm{~N}$ potassium dichromate solution. The equivalence point was fixed potentiometrically. The setup circuit for the analysis is similar to the previous scheme (Figure 6), but without the usage of a lithium-selective electrode. $\mathrm{LiFePO}_{4} / \mathrm{C}$ dissolution in an acidic medium can be observed by the change in the Ox-Red potential of solution when an LFP/C powder sample is added into the solution (Figure 8a). The change in the Ox-Red solution potential is due to the formation of a new Ox-Red pair $\left(\mathrm{Fe}^{3+} / \mathrm{Fe}^{2+}\right)$. The of $\mathrm{Fe}^{3+}$ ions are the result of the powder's partial oxidation. The complete dissolution of the sample is confirmed by the Ox-Red potential plateau. A suspension of insoluble carbon interferes with the visual determination of the equivalence point during titration with $\mathrm{K}_{2} \mathrm{Cr}_{2} \mathrm{O}_{7}$, so fixation of the equivalence point was carried out potentiometrically.
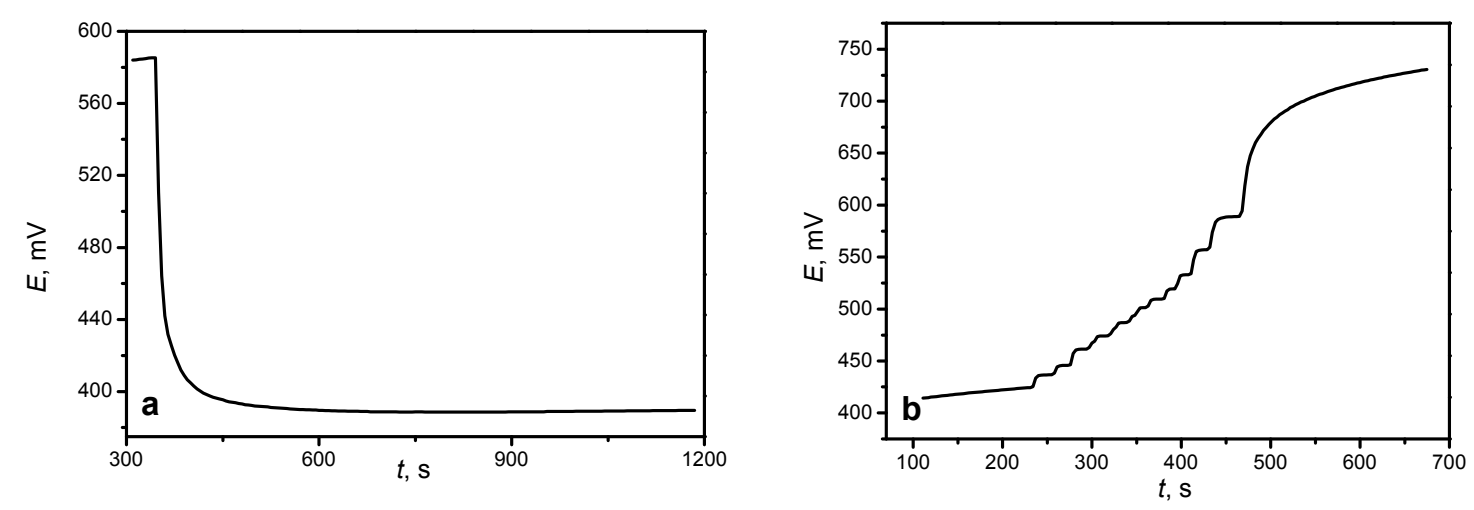

Figure 8. The change in the Ox-Red potential over time: (a) in the LiFePO4/C dissolution process; (b) in the titration process.

When the equivalence point was reached, a sharp jump in the potential was registered due to the formation of a new Ox-Red pair $\left(\mathrm{Cr}_{2} \mathrm{O}_{7}{ }^{2-} / \mathrm{Cr}^{3+}\right)$ (Figure 8b). The established Ox-Red potential of the solution increased insignificantly after the jump, followed a plateau, which suggests the complete oxidation reaction.

The oxidation degree of synthesized $\mathrm{LiFePO}_{4} / \mathrm{C}$ according to the results of titration in an acidic medium is $91.5 \%$. This value is reproducible and the average error is only $0.2 \%$.

To confirm the efficiency of this method, the synthesized $\mathrm{LiFePO}_{4} / \mathrm{C}$ was half oxidized $(t=200 \mathrm{~s})$ and completely oxidized $(t=2000 \mathrm{~s})$, respectively, in alkaline medium by hydrogen peroxide (at room temperature) followed by the filtration and drying of the powder. For the determination of the oxidation degree, the latter obtained samples were analyzed by Mossbauer spectroscopy, $\mathrm{XRD}$, and chemical oxidation method in acidic medium. XRD patterns indicate the presence of two phases (olivine and heterozite) in the case of half-oxidized material (Figure 9a) and only the heterozite phase for completely oxidized material (Figure 9b).

The oxidation degree of half-oxidized and completely oxidized LFP determined by Mössbauer spectroscopy is $45.2 \%$ and $100 \%$, respectively. This is in good agreement with the results of the titrimetric method $-4.8 \%$ and $100 \%$, respectively.

The good correlation between Mössbauer spectroscopy and titrimetric method indicates the validity of the suggested analysis method, but without additional XRD analysis it cannot be affirmed that all titrated $\mathrm{Fe}^{2+}$ ions are found only in $\mathrm{LiFePO}_{4}$. The chemical oxidation method in acidic medium is convenient for application in laboratory studies. Better results can be achieved by optimizing LFP synthesis and improving the determination of the carbon content from the sample. 


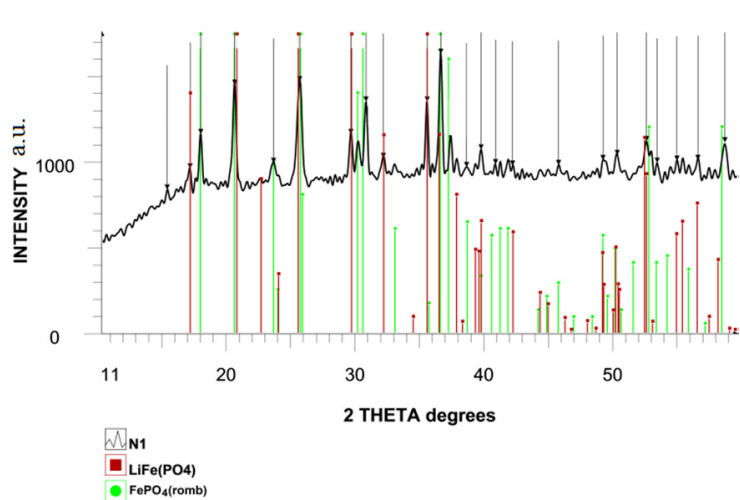

(a)

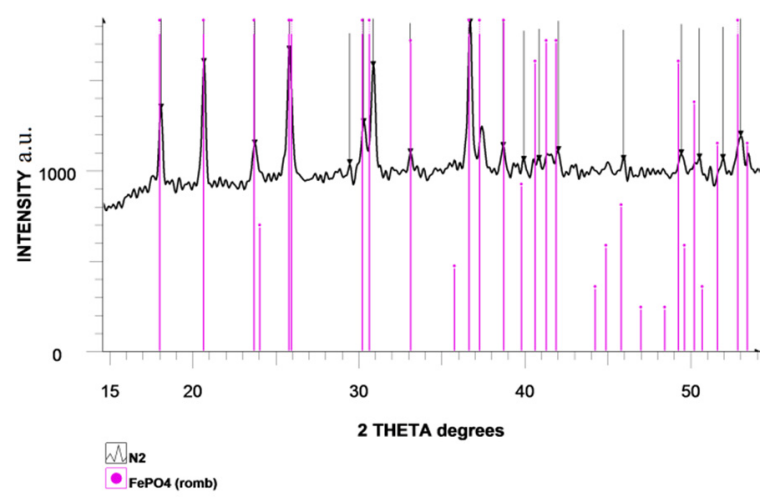

(b)

Figure 9. XRD patterns of (a) half-oxidized and (b) completely oxidized LFP/C, respectively.

\section{Conclusions}

$\mathrm{LiFePO}_{4}$ was successfully synthesized by the carbothermal method, using as-synthesized $\mathrm{FePO}_{4} \cdot 2 \mathrm{H}_{2} \mathrm{O}$ and commercial LiAc. The material was characterized by XRD and Mössbauer spectroscopy. The charge and discharge capacity of the synthesized material, at a current rate of $0.1 \mathrm{C}$, reach values of 154.1 and $152.7 \mathrm{mAh} / \mathrm{g}$, respectively. When the material was tested at higher current rates, the following capacities values (mAh/g) were obtained: 145.5 (1 C), 132.3 (2 C), 113.1 (5 C), 91.2 (10 C) and $65(20 \mathrm{C})$, respectively.

A comparative analysis of oxidation degree determination of the synthesized $\mathrm{LiFePO}_{4} / \mathrm{C}$ by four different methods (Mössbauer spectroscopy, coulometric, oxidation of the material in an alkaline medium, and oxidation of the material in an acidic medium) has been performed. The simplest and most reliable method for determination of the degree of oxidation of the material is the titrimetric method in an acid medium. The results of titrimetric analysis are in good agreement with the data obtained by Mossbauer spectroscopy. In some cases, there is no need to use sophisticated instrumental methods to determine the oxidation degree of the material. However, XRD analysis clarifies/proves that all the detected divalent iron ions are included in the LFP structure.

Acknowledgments: This work was supported by the grant from the Ministry of Education and Science of the Republic of Kazakhstan: 0143/PCF; 4186/GF4.

Author Contributions: M.F. and K.A. performed the experiments analyzed data and wrote the paper (these authors contributed equally to this work), G.A. performed the experiments analyzed data, K.D. performed electrochemical analysis and M.A.-H. helped to wrote the paper.

Conflicts of Interest: The authors declare no conflict of interest.

\section{References}

1. Padhi, A.K.; Nanjundaswamy, K.S.; Goodenough, J.B. Phospho-olivines as positive electrode materials for rechargeable lithium batteries. Electrochem. Soc. 1997, 44, 1188-1194. [CrossRef]

2. Li, J.; Yao, W.; Martin, S.; Vaknin, D. Lithium ion conductivity in single crystal $\mathrm{LiFePO}_{4}$. Solid State Ionics 2008, 179, 2016-2019. [CrossRef]

3. Barker, J.; Saidi, M.Y.; Swoyer, J.L. Lithium iron (II) phospho-olivines prepared by a novel carbothermal reduction method. Electrochem. Solid-State Lett. 2003, 6, 53-55. [CrossRef]

4. Tang, K.; Yu, X.; Sun, J.; Li, H.; Huang, X. Kinetic analysis on $\mathrm{LiFePO}_{4}$ thin films by CV, GITT, and EIS. Electrochem. Acta 2011, 56, 4869-4875. [CrossRef]

5. Hu, G.R.; Gao, X.G.; Penh, Z.D.; Du, K.; Liu, Y.J. Synthetic $\mathrm{LiFePO}_{4} / \mathrm{C}$ without using inert gas. Chin. Chem. Lett. 2007, 18, 337-440. [CrossRef] 
6. Chen, C.; Liu, G.B.; Wang, Y.; Li, J.L.; Liu, H. Preparation and electrochemical properties of $\mathrm{LiFePO}_{4} / \mathrm{C}$ nanocomposite using $\mathrm{FePO}_{4} \cdot 2 \mathrm{H}_{2} \mathrm{O}$ nanoparticles by introduction of $\mathrm{Fe}_{3}\left(\mathrm{PO}_{4}\right)_{2} \cdot 8 \mathrm{H}_{2} \mathrm{O}$ at low cost. Electrochim. Acta 2013, 113, 464-469. [CrossRef]

7. Ou, X.Q.; Xu, S.Z.; Liang, G.C.; Wang, L.; Zhao, X. Effect of Fe(III) impurity on the electrochemical performance of $\mathrm{LiFePO}_{4}$ prepared by hydrothermal process. Sci. Chin. Ser. E Technol. Sci. 2009, 52, 264-268. [CrossRef]

8. Malchik, F.I.; Kurbatov, A.P. Study of the kinetic of $\mathrm{LiFePO}_{4}$ oxidation in aqueous solution. In Proceedings of the 66th Annual Meeting of the International Society of Electrochemistry, Tapei, Taiwan, 4-9 October 2015; p. 507.

9. Zhu, Y.; Wang, C. Galvanostatic intermittent titration technique for phase-transformation electrodes. J. Phys. Chem. 2011, 114, 2830-2841. [CrossRef]

10. Trinh, N.D.; Liang, G.; Gauthier, M.; Schougaard, B. A rapid solution method to determine the charge capacity of $\mathrm{LiFePO}_{4}$. J. Power Source 2012, 200, 92-97. [CrossRef]

11. Jones, J.L.; Hung, J.T.; Meng, Y.S. Intermittent X-ray diffraction study of kinetics of delithiation in nano-scale $\mathrm{LiFePO}_{4}$. J. Power Source 2009, 189, 702-705. [CrossRef]

12. Lepage, D.; Sobh, F.; Kuss, C.; Liang, G.; Schougaard, S.B. Delithiation kinetics study of carbon coated and carbon free $\mathrm{LiFePO}_{4}$. J. Power Source 2014, 256, 61-65. [CrossRef]

13. Zhang, L.; Liang, G.; Ignatov, A.; Croft, M.C.; Xiong, X.; Ming Hung, I.; Huang, Y.; Hu, X.; Zhang, W.; Peng, Y. Effect of Vanadium Incorporation on Electrochemical Performance of $\mathrm{LiFePO}_{4}$ for Lithium-Ion Batteries. J. Phys. Chem. 2011, 115, 13520-13527.

14. Luo, S.; Tang, Z.; Lu, J.; Zhang, Z. Electrochemical properties of carbon-mixed $\mathrm{LiFePO}_{4}$ cathode material synthesized by the ceramic granulation methods. Ceram. Int. 2008, 34, 1349-1351. [CrossRef]

15. Yu, D.Y.W.; Donoue, K.; Kadohata, T.; Murata, T.; Matsuta, S.; Fujitani, S. Impurities in LiFePO4 and Their Influence on Material Characteristics. Electrochem. Soc. 2008, 155, 526-530. [CrossRef]

(C) 2017 by the authors. Licensee MDPI, Basel, Switzerland. This article is an open access article distributed under the terms and conditions of the Creative Commons Attribution (CC BY) license (http:/ / creativecommons.org/licenses/by/4.0/). 